\section{After human: The world of brain-net on earth}

\author{
Sadique Shaikh* \\ AIMSR, Jalgaon, M.S, India
}

\section{Interaction}

"The mind of man is capable of anything....because everything in in it, all the past as well as all the future [Joseph Conrad]". Why I am using above quote and what is the relation to what point I am coining you will understand its relevant your own as you moving line by line of this write-up. This topic though complex to some people to get understand, but those has strong or at least average background of Space, Physics, Quantum Mechanics, Neuroscience and theory of evolution definitely acquire it. Near distance and physical face to face communication started with the evolution of humankind and changes in each evolution in DNA structure caused to changes in communication patterns from different phonetics to gestures, gestures to voice and voice to voice with different languages. But first remote distance communication we can only considered to post office Communication with written language on papers and remain long time one of the biggest but very slow source of remote communication from one person to another person, than after telegram and radio communication came in existence but fairly good and very expensive with charges per words in line to send from one person to another person. Great phase shift occurred in the world when electronic communication system successes with telephones and walky talky, pagers and satellite phones which are several times instant as compared to all mentioned traditional communication systems, but mankind not settled with this and computer and mobiles communication begin to rule whole world as very instant sources of communication with World Wide Web (WWW) called "Internet" of Computers further due to smart phones tends to Internet of Mobiles/ Smart Phones. Since 1999 to 2013 "Internet of Computer (IoC)" boomed and with rapid and abrupt advancement of mobile phones which are equal or more powerful, accurate, fast and instant as compare to computers with high connectivity to WWW world shifted to next level "Internet of Mobile (IoM)" and lot of physical aspects even can say 35\% physical aspects of human routine transformed to virtually or electronically using it. Since 2015 one term rushes in world called "Internet of Things (IoT)" and the concept is here all living things like Human, Animals and all can communicate

\section{More Information}

*Address for Correspondence:

Dr. Md. Sadique Shaikh, Professor, AIMSR, Jalgaon, M.S, India,

Email: sids_nsk@rediffmail.com

Submitted: December 15, 2020

Approved: January 22, 2021

Published: January 25, 2021

How to cite this article: Shaikh S. After human: The world of brain-net on earth. J Neurosci Neurol Disord. 2021; 5: 004-005.

DOI: 10.29328/journal.jnnd.1001043

Copyright: @ 2021 Shaikh S. This is an open access article distributed under the Creative Commons Attribution License, which permits unrestricted use, distribution, and reproduction in any medium, provided the original work is properly cited.

Check for updates

OPEN ACCESS

using Ubiquitous Communication Network (UCN) and Radio Frequency IDentification (RFID) modules which is unique for each one connected in IoT across the globe. This technology further researches, engineered, refined and polished as what available at present with us in 2020 called "Internet of Everything (IoE)" where not only living creatures like, Human, animals, mammoths etc. but also 'Non-living' things like all automobiles, transportations, buildings, furniture's, consumers and kitchen and home appliances, almost everything of entire world connected in UCN with their unique RFID. Now the next two levels with connections possibilities I am explaining here after World Wide Web (WWW) next two are Planets Wide Web (PWW) where all planets of our solar system or interstellar space can communicate with each other with human and other alien's civilizations in near future. With further expansion Universe Wide Web (UWW) where all Universe planets, asteroids, moons, stars and their aliens civilization can communicate with each other also with mankind but when this happen human changed its present form due to the change in human DNA structure which vanishes all human body parts and organs which mankind not using since long time in far future. Analogically you can take example of your computer or smart phones the software's or files those you are not using since long time operating system ask you to delete or remove all unused. Because of advanced Artificial Intelligence and automation human using machines for their minor to minor or major to major work instead of body parts like hands, legs, eyes, mouth etc. therefore DNA structure will start to remove all unused body parts of human and finally the main processor "Brains" left in entre world with 
brains civilization instead of human civilization. In USA, Japan and China already research success and reach to next level to connect one human brain with another human brain using sensors and actuators advanced electronic/optical A.I based communication network and data/information from one brain to another brain directly possible to send without typing and speaking a single word of language using modulation and demodulation of thoughts or fired neurons schemas as transmission and reception frequencies or thoughts frequency. After human or after human body is just a brain with vanished all body parts and connected across the world with each other with "Thoughts and Consciousness" of human brain. Now if such would be happen that what about human 'Sex and Population' how mankind reproduction to sustain its identity because if only brain left in world as after human form which are "Unisex" I.e. all males and females brain are same in nature and unisex hence how reproduction possible in that case every Brain create its Clones Brain as its family. All brain directly +transmit and receive data/information, copy data/ information or uploads downloads data, information, files , delete or modify, update date/information from one brain to another brain with ultra high instant communication speed called this ultimate network "Internet of Mind " or "Brain-Net". Perhaps this Brain-Net also we can say "Net of Consciousness" where all past, present and future already in brain which reflect outside as illusion what we call our "Reality". Here analogically you can take example of Electronic projector or Holographic projector where everything is processed inside projector and what observe outside is just reflections of lights with different refractive and reflective index in the form of pictures or motion pictures but if you want to touch it physically you won't. Similarly everything processed inside Brain as consciousness and out as Reality front of our eyes for our eyes and through/by our eyes. In last I would like to remark that Everything the World, The Universe, The Multiverse, Human Relations, Love, Religions, Wealth, and all are just a "Consciousness" of Brain with different pattern of "Reality Illusions" projected out from our brains to see everything with different "Perceptions" likes and dislikes called "Mind" and to control and educate it called the "Wisdom" of Mind. Hence "Brain-Net" would be "Net of Consciousness (NoCon)" with WWW, than PWW and ultimately UWW communication network technologies in future up to the year 2090 and after years of it, and the factual data in this direction in September 2020 Japan launched its first "Quantum Internet" with coverage $400 \mathrm{KM}$ and connecting 4 metro cities successfully. But off course I admit The God exist, the power who created this consciousness with illusions ability in Human Brain. But Consciousness has no religions, no belief or ideology, no gender, no sexuality, no race, no age and no nationality. You ARE Consciousness...therefore pray to the power not picture and live in future with "Internet of Consciousness (IoCon)". In last I would like to conclude advanced level engineering and studies in Neuroscience (Natural Intelligence) and Robotics (Artificial Intelligence) how possibly and across the universe wide we can hybrid and connect these two to transmit and receive direct data and information in fraction of science using Data Science, storage, advance communication and space science. 